\title{
Non-thermal atmospheric plasma induces ROS-independent cell death in U373MG glioma cells and augments the cytotoxicity of temozolomide
}

Gillian E Conway ${ }^{\star}, 1,2,3$, Alan Casey ${ }^{3}$, Vladimir Milosavljevic ${ }^{1}$, Yupeng Liu ${ }^{4}$, Orla Howe ${ }^{3,5}$, Patrick J Cullen ${ }^{1,6}$ and James F Curtin ${ }^{*, 1,2}$

${ }^{1}$ BioPlasma Research Group, School of Food Science and Environmental Health, Dublin Institute of Technology, Dublin, Ireland; ${ }^{2}$ Environmental Sustainability and Health Institute, Dublin Institute of Technology, Dublin, Ireland; ${ }^{3}$ FOCAS Research Institute, Dublin Institute of Technology, Dublin, Ireland; ${ }^{4}$ School of Computing, Dublin Institute of Technology, Dublin, Ireland; ${ }^{5}$ School of Biological Sciences, Dublin Institute of Technology, Dublin, Ireland and ${ }^{6}$ School of Chemical Engineering, UNSW, Sydney, Australia

Background: Non-thermal atmospheric plasma (NTAP) is an ionised gas produced under high voltage that can generate shortlived chemically active species and induce a cytotoxic insult in cancer cells. Cell-specific resistance to NTAP-mediated cytotoxicity has been reported in the literature. The aim of this study was to determine whether resistance against NTAP could be overcome using the human glioma cell line U373MG.

Methods: Non-thermal atmospheric plasma was generated using a Dielectric Barrier Device (DBD) system with a maximum voltage output of $120 \mathrm{kV}$ at $50 \mathrm{~Hz}$. The viability of U373MG GBM cells and HeLa cervical carcinoma cells was determined using morphology, flow cytometry and cytotoxicity assays. Fluorescent probes and inhibitors were used to determine the mechanisms of cytotoxicity of cells exposed to the plasma field. Combinational therapy with temozolomide (TMZ) and multi-dose treatments were explored as mechanisms to overcome resistance to NTAP.

Results: Non-thermal atmospheric plasma decreased cell viability in a dose (time)-dependent manner. U373MG cells were shown to be resistant to NTAP treatment when compared with HeLa cells, and the levels of intracellular reactive oxygen species (ROS) quantified in U373MG cells were much lower than in HeLa cells following exposure to the plasma field. Reactive oxygen species inhibitor $\mathrm{N}$-acetyl cysteine (NAC) only alleviated the cytotoxic effects in HeLa cells and not in the relatively NTAP-resistant cell line U373MG. Longer exposures to NTAP induced a cell death independent of ROS, JNK and caspases in U373MG. The relative resistance of U373MG cells to NTAP could be overcome when used in combination with low concentrations of the GBM chemotherapy TMZ or exposure to multiple doses.

Conclusions: For the very first time, we report that NTAP induces an ROS-, JNK- and caspase-independent mechanism of cell death in the U373MG GBM cell line that can be greatly enhanced when used in combination with low doses of TMZ. Further refinement of the technology may facilitate localised activation of cytotoxicity against GBM when used in combination with new and existing chemotherapeutic regimens.

*Correspondence: GE Conway; E-mail: gillian.conway@mydit.ie or Dr JF Curtin; E-mail: james.curtin@dit.ie

Received 19 October 2015; revised 8 December 2015; accepted 16 December 2015; published online 4 February 2016

(c) 2016 Cancer Research UK. All rights reserved 0007-0920/16 
Glioblastoma multiforme (GBM) is classified as a malignant grade IV astrocytoma (Louis et al, 2007), and is considered to be the most biologically aggressive brain tumour that accounts for approximately $16 \%$ of all brain tumours (Dolecek et al, 2012). According to the 2014 Central Brain Tumor Registry of United States (CBRTUS) report, GBM makes up approximately $45.6 \%$ of all primary malignant brain tumours. The prognosis for patients diagnosed with GBM is bleak with a 5-year survival rate of $<10 \%$ (Ostrom et al, 2014). The current standard of care for GBM is maximal surgical resection followed by radiotherapy and concomitant and adjuvant chemotherapy using temozolomide (TMZ) (Adamson et al, 2009). Treatment for GBM is limited due to the inability of most chemotherapeutics to cross the blood brain barrier to the site of the tumour and failure to successfully remove all surrounding tumour cells during surgical resection (Candolfi et al, 2007). Thus, survival rates have remained relatively stagnant over the past 30 years (Carrabba et al, 2009). Recent statistics provided by Ostrom et al (2014) show that patients diagnosed have a 1 -year survival rate of $36.5 \%$, which drops dramatically after 3 years to $8.7 \%$, indicating the urgency for the development of new therapies.

Over the past decade, plasma science has emerged as a novel approach for applications in areas such as food sterilisation, medical devices, polymer science and biomedicine (von Woedtke et al, 2013; Ziuzina et al, 2014). Physical plasmas are fully or partially ionised gases that contain various concentrations of free electrical charges, atoms, ions and electrons, which are generated by an energy supply to a neutral gas (von Woedtke et al, 2013). Plasmas can be categorised as either thermal or non-thermal. Nonthermal plasma (NTP) gains its reactivity from the high energy electrons while the ions and neutral species remain at a low temperature (von Woedtke et al, 2013). NTPs attained at low or atmospheric pressure have low power requirements and are also able to generate chemically active species within gasses such as reactive oxygen species (ROS) $\left(\mathrm{O}_{2}^{\bullet}, \mathrm{O}\right.$, and $\left.\mathrm{O}_{3}, \mathrm{OH}^{\bullet}, \mathrm{H}_{2} \mathrm{O}_{2}\right)$ and reactive nitrogen species (RNS) $\left(\mathrm{NO}_{3}, \mathrm{~N}_{2}^{+}, \mathrm{NO}\right)$. The operating principle of the plasma discharge system used is Dielectric Barrier Discharge (DBD), which generates high voltage pulsed nonthermal plasma between two electrodes, one of which is insulated. The insulator prevents the build-up of current between the electrodes and any significant gas heating (Fridman et al, 2006). Non-thermal atmospheric plasma can effectively control the concentrations of intracellular ROS/RNS. Non-thermal atmospheric plasma-generated $\mathrm{NO}$ species results in the elevation of intracellular NO concentration, which therefore leads to an increase in intracellular ROS (Vandamme et al, 2012; Ishaq et al, 2014).

Reactive oxygen species are naturally present in the body and at low concentrations mediate many biological functions including cellular redox signalling, and high concentrations of ROS are utilised as a cytotoxic mechanism by innate immune cells (Ahn et al, 2011). To prevent cellular damage and apoptosis due to the high reactivity of ROS, the cell contains antioxidant enzymes such as glutathione peroxidase, which act as scavengers to detoxify ROS (King and Robins, 2006). Over the years, it has become increasingly apparent that the generation of ROS can be utilised therapeutically for the treatment of cancer (Curtin et al, 2002). Temozolomide is an alkylating agent, used in the treatment of GBM that induces cell death by an ROS/ERK-mediated apoptosis (Lin et al, 2012). A recurring issue with the current chemotherapeutics used in the treatment for GBM is the adverse side effects induced due to the high toxicity of the drugs, and developed resistance to the therapeutic over time. Combinational therapies are used with the aim to reduce the likelihood of developing drug resistance and reduce the adverse side effects associated with single agent therapies. It is hypothesised that NTAP offers great potential as a possible combinational therapy for the treatment of GBM due to the wide variety of biological processes affected.
Recent studies have shown that high concentrations of ROS produced from NTAP exposure can generate a cytotoxic effect and induce apoptosis of cancer cells via disruption of the mitochondrial membrane (Fridman et al, 2008; Ahn et al, 2011; Vandamme et al, 2012; Köritzer et al, 2013). An important feature that has been demonstrated in previous studies is that NTAP not only has the ability to induce cell death in GBM cells but also has a much lower cytotoxic effect on normal astrocytes (Recek et al, 2015; Siu et al, 2015). Although there is vast potential for the use of NTAP both as a single agent and as a combinational therapy in the treatment of cancers, experimental evidence supporting this application in GBM remains to be carried out. The aim of this study is to evaluate the antitumour effects of NTAP using a DBD system in vitro on U373MG glioblastoma cells, and to determine the efficacy of a combinational approach using TMZ.

\section{MATERIALS AND METHODS}

Cell culture. Human glioblastoma (U373MG-CD14) cells were obtained from Dr Michael Carty (Trinity College Dublin). Human cervical cancer (HeLa, ATCC CCL-2) cells were purchased from American Type Culture Collection (LGC Standards, Middlesex, UK). U373MG cells were cultured in DMEM (Sigma-Aldrich, Arklow, Ireland) supplemented with 10\% FBS (Sigma-Aldrich). HeLa cells were cultured in RPMI-1640 (Sigma-Aldrich) with 10\% FBS. Both cell lines were maintained in a humidified incubator containing $5 \% \mathrm{CO}_{2}$ at $37^{\circ} \mathrm{C}$. Media was changed every 2-3 days until $80 \%$ confluency was reached. Cells were routinely subcultured using a $1: 1$ ratio of $0.25 \%$ trypsin (Sigma-Aldrich) and 0.1\% EDTA (Sigma-Aldrich) (0.1 g EDTA in $500 \mathrm{ml}$ PBS).

NTAP device. The NTAP-DBD device used (Figure 1A) is a novel prototype atmospheric low temperature plasma generator (Ziuzina et al, 2013). The system consists of a variable high voltage transformer with an input voltage of $230 \mathrm{~V}$ at $50 \mathrm{~Hz}$ and a maximum high voltage output of $120 \mathrm{kV}$. The two 15 -cm-diameter aluminium disc electrodes were separated by a polypropylene sheet, which served both as a sample holder and as a dielectric barrier with a thickness of $1-2 \mathrm{~mm}$. The distance between the two electrodes was 14.2-26.6 mm depending on the size of culture plate used. Voltage was monitored using an InfiniVision $2000 \mathrm{X}$-Series Oscillo-scope (Agilent Technologies Inc., Santa Clara, CA, USA). The atmospheric air condition at the time of treatment was $45 \%$ relative humidity $(\mathrm{RH})$ and $22^{\circ} \mathrm{C}$. The samples were treated at $75 \mathrm{kV}$ for $0-300 \mathrm{~s}$. Optical emission spectroscopy (OES) readings (Supplementary Figure 1) were taken between the range of 200 and $850 \mathrm{~nm}$ using the Low Straylight Smart CCD Exemplar LS spectrophotometer (B\&W Tek, Inc., Newark, DE, USA; BRC115U), with a 3000-m/s integration time. Data were analysed using BWSpec4 (B\&W Tek, Inc.) and OriginPro 8 (OriginLab Corporation, Northampton, MA, USA).

Cell viability assays. U373MG cells were seeded at a density of $1 \times 10^{4}$, and HeLa cells were seeded at $0.8 \times 10^{4}$ into 96-well plates (Sigma-Aldrich) and allowed to adhere overnight. Media was removed for the duration of NTAP treatment, and fresh media was replaced immediately after treatment and incubated at $37^{\circ} \mathrm{C}$ as indicated. No deleterious effects were observed in the vehicle control samples.

Cell viability was analysed using Alamar Blue, a redox fluorogenic indicator of metabolic reduction (Fischer Scientific, Ballycoolin, Ireland) (Page et al, 1993). Cells were washed once with sterile PBS, incubated for $2.5 \mathrm{~h}$ at $37^{\circ} \mathrm{C}$ with a $10 \%$ Alamar blue solution, and fluorescence was measured using an excitation wavelength of $530 \mathrm{~nm}$ and an emission wavelength of $595 \mathrm{~nm}$ on a Victor 3V 1420 (Perkin Elmer, Waltham, MA, USA) multi-plate reader. The Trypan Blue (Biosciences, Dun Laoghaire, Ireland) cell dye exclusion assay was also performed $48 \mathrm{~h}$ post treatment in 
A
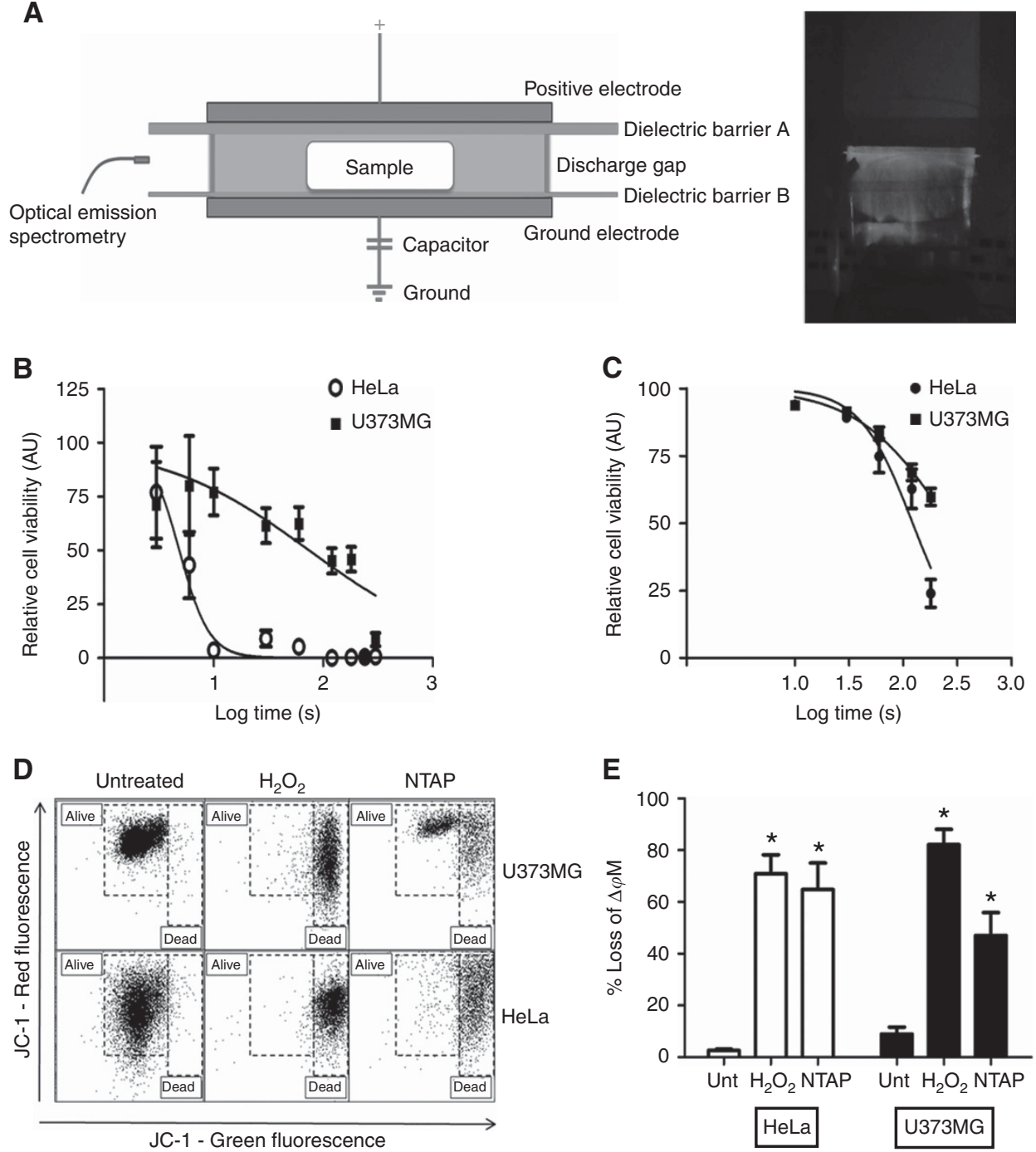

Figure 1. NTAP dose-dependent cytotoxicity of HeLa and GBM cells. (A) Schematic of the DBD-NTAP set-up used in this study, and a photograph showing plasma generation which fluoresces in the presence of helium gas. (B) Both U373MG cells and HeLa cells were exposed to NTAP at $75 \mathrm{kV}$ for up to $5 \mathrm{~min}$. Forty-eight hours later, the cells were analysed using the Alamar Blue cell viability assay. All experiments were repeated a minimum of three times. Statistical analysis was carried out using non-linear regression analyses. (C) Both U373MG cells and HeLa cells were exposed to NTAP at $75 \mathrm{kV}$ for up to $180 \mathrm{~s}$. HeLa cells were trypsinised and counted using a haemocytometer $48 \mathrm{~h}$ post treatment. U373MG cells were analysed $96 \mathrm{~h}$ post treatment. All experiments were repeated a minimum of three times. Statistical analysis was carried out using non-linear regression analyses. (D) HeLa and U373MG cells were exposed to NTAP at $75 \mathrm{kV}$ for $3 \mathrm{~min}$. After a 48 -h incubation period, cells were loaded with $1 \mu \mathrm{g} \mathrm{ml}^{-1} \mathrm{JC}-1$ dye and analysed by flow cytometry. Data shown depict apoptosis measured by quantitative shifts in the $\Delta \Psi \mathrm{m}$ (red to green) fluorescence intensity ratio before and after $\mathrm{H}_{2} \mathrm{O}_{2}$ and NTAP expsoure. All experiments were repeated in triplicate. Statistical analysis was carried out using one-way ANOVA with Tukey's multiple comparison post-test $\left({ }^{\star} P<0.05\right)$. A full colour version of this figure is available at the British Journal of Cancer journal online.

HeLa cells and $96 \mathrm{~h}$ post treatment in U373MG cells. Both floating and trypsinised cells were collected, and a $1 \times 10^{6}$ cell per ml cell suspension was prepared. A 1:1 mixture of cell suspension and $0.4 \%$ trypan blue was loaded onto a haemocytometer for counting.

JC-1 apoptosis assay. After treatment, cells were harvested and stained with $10 \mu \mathrm{g} \mathrm{ml}^{-1} \mathrm{JC}-1$ dye (Biosciences, Dublin, Ireland) (Galluzzi et al, 2007), at room temperature for $10 \mathrm{~min}$ and analysed by flow cytometry (BD Accuri C6, BD Biosciences, Erembodegem, Belgium). JC-1 was excited using the argon laser at a wavelength of $488 \mathrm{~nm}$. Fluorescence was measured using the FL1 $(530 \mathrm{~nm})$ and FL2 $(585 \mathrm{~nm})$ channels with emission spectral overlap compensation $(7.5 \%$ FL1/FL2 and 15\% FL2/FL1).

Fluorescent probes. Reactive oxygen species generation was determined using the cell permeable non-fluorescent probe $\mathrm{H}_{2}$ DCFDA (Biosciences, Dublin, Ireland) (Wu and Yotnda, 2011). Cells were plated in black flat-bottomed 96-well plates
(Fischer Scientific) overnight and preloaded with $10 \mu \mathrm{M} \mathrm{H} \mathrm{H}_{2}$ DCFDA for $1 \mathrm{~h}$. Cells were washed once with PBS and exposed to NTAP for $180 \mathrm{~s}$ at $75 \mathrm{kV}$ or treated with $\mathrm{H}_{2} \mathrm{O}_{2}$ where indicated. After NTAP treatment, media was added to the wells and fluorescence intensity was measured $1 \mathrm{~h}$ later on a micro-plate reader (Victor $3 \mathrm{~V}$ ) at $492-$ 495/517-527 nm. For fluorescent images, U373MG and HeLa cells were plated in $35 \mathrm{~mm}$ glass bottom dishes (MatTek Corporation, Ashland, MA, USA) at $5 \times 10^{4}$ and $8 \times 10^{4}$ cells per dish respectively and left for $24 \mathrm{~h}$. Cells were preloaded and treated as stated above and analysed using confocal microscopy (ZEISS LSM 510 Meta, Carl Zeiss, Oberkochen, Germany). Images were captured using an excitation wavelength $488 \mathrm{~nm}$ and an emission wavelength of $515 \mathrm{~nm}$ with a $\times 40$ objective. ROS was quantified on the flow cytometer using $\mathrm{H}_{2}$ DCFDA. Cells stained with $0.1 \mu \mathrm{M}$ $\mathrm{H}_{2}$ DCFDA for $30 \mathrm{~min}$ before NTAP treatment. One hour post treatment, cells were harvested and analysed by flow cytometry. Fluorescence was measured using the FL1 channel $(530 \mathrm{~nm})$. 
Mitochondrial ROS production was determined using MitoSOX Red (Biosciences, Dublin, Ireland). Cells were loaded with $2 \mu \mathrm{M}$ MitoSOX red, a mitochondrial superoxide indicator. Cells were incubated for $10 \mathrm{~min}$ at $37^{\circ} \mathrm{C}$ and analysed by confocal microscopy. Images were captured using an excitation wavelength $510 \mathrm{~nm}$ and an emission wavelength of $580 \mathrm{~nm}$ with a $\times 40$ objective. The total cell fluorescence was calculated using the Image (v1.49, NIH) software. An outline was drawn around each individual cell, as previously described by McCloy et al (2014) the total corrected fluorescence was then calculated as follows: total corrected cell fluorescence $(\mathrm{TCCF})=$ integrated density - (area of selected cell $\times$ mean fluorescence of background readings).

Inhibitor studies. As indicated in the relevant figures, cells were pre-treated for $1 \mathrm{~h}$ with zVAD-FMK (BD Bioscience, Oxford, England), or were incubated with $\mathrm{N}$-acetyl cysteine (NAC) (SigmaAldrich) or SP600125 (Sigma-Aldrich) immediately after NTAP treatment. Cell viability was assessed $48 \mathrm{~h}$ later using Alamar Blue.

Combined treatment of TMZ and NTAP. Cells were seeded at $2.5 \times 10^{3}$ cells per well in 96-well plates. Following NTAP treatment, TMZ (Sigma-Aldrich) was added to the wells at various concentrations. Cells were incubated for 6 days and analysed using the Alamar blue cell viability assay.

Statistical analysis. All experiments were performed at least three independent times with a minimum of five replicates per experiment. Data shown are pooled and presented as mean \pm s.e.m. ( $n=$ total number of replicates) unless stated otherwise. Statistical analysis and curve fitting were performed using Prism 5 (GraphPad Software, Inc., La Jolla, CA, USA), as indicated in Results. Unless otherwise indicated, differences were considered significant with a $P$-value of $<0.05$ Correlation graphics were attained using $\mathrm{R}$ statistical software (The $\mathrm{R}$ Foundation for Statistical Computing, Vienna, Austria).

\section{RESULTS}

NTAP induces apoptosis in cancer cells. Previous studies have suggested that NTAP has an antitumour effect in vitro in cell lines, such as cervical, colorectal, lung cancer, and glioma (Ahn et al, 2011; Köritzer et al, 2013; Cheng et al, 2014; Ma et al, 2014; Siu et al, 2015). Despite the wide range of different NTAP-generating devices being used worldwide, evidence is emerging that cell typespecific resistance can be observed in tumour cells and GBM cells (and other brain-derived cells) appear to be relatively resistant to NTAP. We compared the sensitivity of U373MG GBM cells with a commonly used human cervical carcinoma cell line (HeLa) (Ahn et al, 2011, 2014; Kim et al, 2014).

Dose response curves were established by first exposing cells to NTAP for between 3 and $300 \mathrm{~s}$ at $75 \mathrm{kV}$, as seen in Figure 1B. Cell viability was quantified $48 \mathrm{~h}$ post treatment. We confirmed findings by Ahn et al (2014) that HeLa cells are sensitive to NTAP, using our system the $\mathrm{IC}_{50}$ value was determined to be $4.8 \mathrm{~s}$ (95\% confidence range of 4.2-5.6s). U373MG GBM cells, however, exhibited a significant increase in resistance to NTAP with an $\mathrm{IC}_{50}$ of $74.26 \mathrm{~s}(95 \%$ confidence range of 47.24-116.8 s). A comparison of fit demonstrated a significant difference in the $\mathrm{IC}_{50}$ values $(P<0.05)$ between both the U373MG and HeLa as a result of NTAP treatment, and significant differences of the data set were confirmed using a correlation analysis (Supplementary Figure S2). The cytotoxic response was confirmed using the trypan blue cell membrane integrity assay, and U373MG cells demonstrate a significantly $(P<0.001)$ higher resistance to the NTAP treatment than that observed by the HeLa cells after $180 \mathrm{~s}$ treatment as demonstrated in Figure 1C.

$\Delta \Psi \mathrm{m}$ is an important factor of mitochondrial function and can be an indicator of early intrinsic apoptosis. Collapse of the $\Delta \Psi \mathrm{m}$ results in the release of cytochrome $\mathrm{C}$ into the cytosol, and thus leading to cell death (Salido et al, 2007). Figure 1D demonstrates the loss in Mitochondrial Membrane Potential $(\Delta \Psi \mathrm{m})$ due to NTAP treatment. Both cell lines show a significant $(P<0.05)$ loss in mitochondrial function, indicating a reduction in cell viability after NTAP treatment when compared with untreated controls. This result correlates with both the Alamar Blue and trypan blue results, indicating that NTAP induces differential cytotoxicity in HeLa and U373MG cells.

NTAP induces mitchondrial ROS formation in cancer cells in situ. Recent literature using HeLa and GBM cell lines has stated that NTAP-generated ROS causes DNA damage resulting in apoptosis (Vandamme et al, 2012; Cheng et al, 2014). It is also well known that mitcohondrial depolarisation can be a result of oxidative stress produced by ROS (Ahn et al, 2011). To determine that the cytotoxicity observed was from ROS generated by NTAP, both cell lines were preloaded with the cell permeable ROSsensitive fluorescence dye, $\mathrm{H}_{2}$ DCFDA. Reactive oxygen species generation was first visualised using confocal microscopy, and we confirmed that NTAP induced ROS-dependent $\mathrm{H}_{2}$ DCFDA fluorescence in both cell lines. The level of fluorescence in U373MG cells appeared to be lower than that oberseved in HeLa cells (Figure 2A), and this was then confirmed using both spectrophotometry and flow cytometry. As seen in Figure 2B, significantly higher levels of ROS fluorescence were observed following NTAP treamtent in HeLa cells $(P<0.05)$, compared with untreated controls and with NTAP-treated U373MG cells $(P<0.05)$. A similar result was also obsereved by flow cytometry as demonstrated in Figure 2C. Non-thermal atmospheric plasma treatment demonstrated a significant increase in ROS generation $(P<0.001)$ compared with the untreated control in HeLa cells. A slight dextral shift was observed in U373MG cells, but the meausred mean fluorescence index was not signicantly altered. Following the identification of ROS formation by $\mathrm{H}_{2}$ DCFDA, cells were treated with mitochondrial superoxide indicator, MitoSOX red. Mitochondrial ROS production as a result of NTAP treatment has been previuously demonstrated in HeLa cell by Ahn et al (2014), Figure 2D demonstrates the increase in intracellular fluorescence of mitochondrial ROS formation by confocal micrscopy in both HeLa and U373MG cells compared with the untreated control. The level of fluorescence was quantified using ImageJ (v1.49, NIH) software in both treated and untreated cells (McCloy et al, 2014). There is a significant increase in mitochondrial ROS after NTAP treamtent observed in both U373MG $(P<0.05)$ and HeLa cells $(P<0.001)$ compared with the untreated controls.

GBM cells demonstrate higher antioxidant activity against $\mathbf{H}_{2} \mathrm{O}_{2}$. The production of a variety of ROS by NTAP, including $\mathrm{H}_{2} \mathrm{O}_{2}$ has been shown previously to induce cytotoxicity (Ahn et al, 2014; Hirst et al, 2015; Xu et al, 2015). These free radicals, particularly the NTAP-generated NO species, are believed to result in an increase in intracellular ROS, which in turn signals a cascade of events leading to apoptosis (Ishaq et al, 2014). As observed from the OES data (Supplementary Figure 1), we have identifed the presence of $\mathrm{OH}$. in our OES mesurements and $\mathrm{OH}$. is generated as a result of $\mathrm{O}_{2}^{-}$and $\mathrm{H}_{2} \mathrm{O}_{2}$ interactions in the plasma field, which as a result induces cell death ( $\mathrm{Xu}$ et al, 2015). We hypothesised that the increased resistance displayed by U373MG cells to NTAP could replicated using $\mathrm{H}_{2} \mathrm{O}_{2}$ as an oxidative stressor. Figure $3 \mathrm{~A}$ demonstrates that U373MG cells indeed have an increased tolerance for $\mathrm{H}_{2} \mathrm{O}_{2}$ compared with that of HeLa cells. The $\mathrm{IC}_{50}$ value for $\mathrm{H}_{2} \mathrm{O}_{2}$ cytotoxicity is significantly higher $(P<0.0001)$ for U373MG cells $(544.8 \mu \mathrm{M})$ compared with HeLa cells $(27.91 \mu \mathrm{M})$, and significant differences of the data set were confirmed using a correlation analysis (Supplementary Figure S3). The generation of $\mathrm{H}_{2} \mathrm{O}_{2}$ was significantly lower in U373MG cells $\left(\mathrm{EC}_{50} 458.1 \mu \mathrm{M}\right)$ 
A
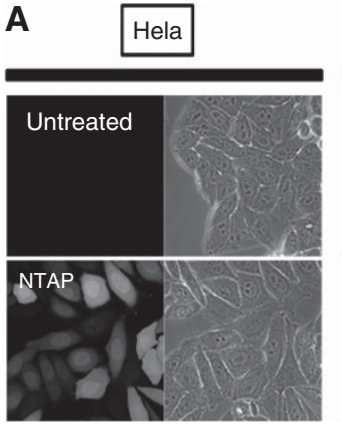

c

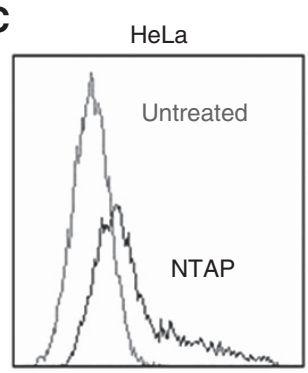

D
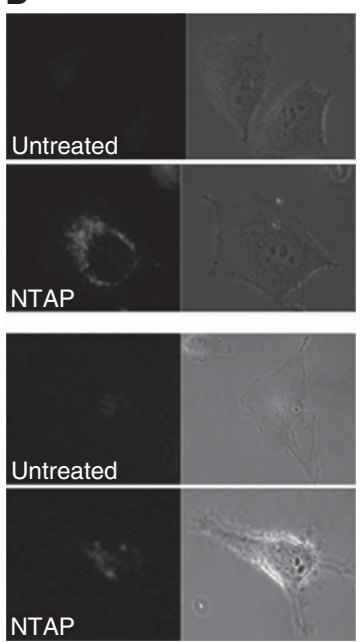

U373MG

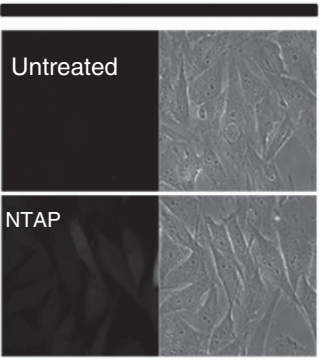

U373MG

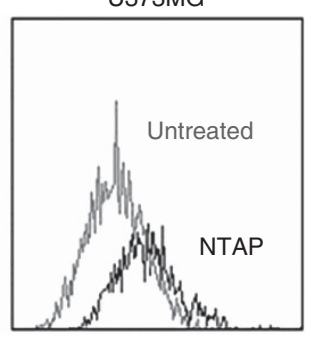

B
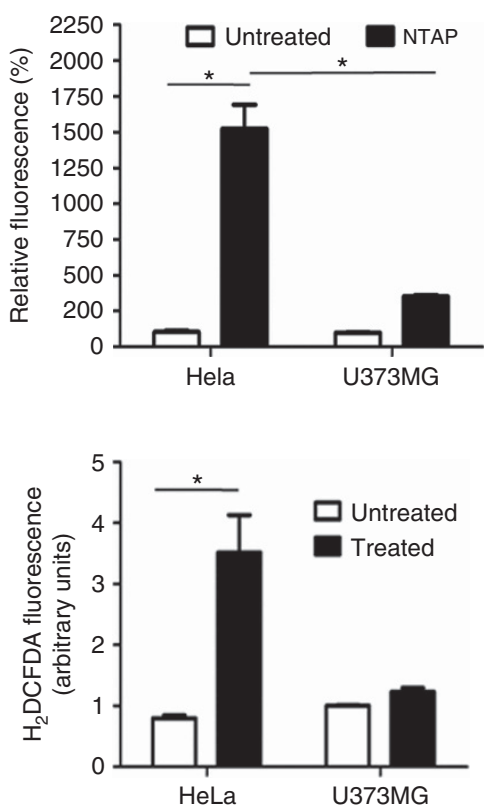
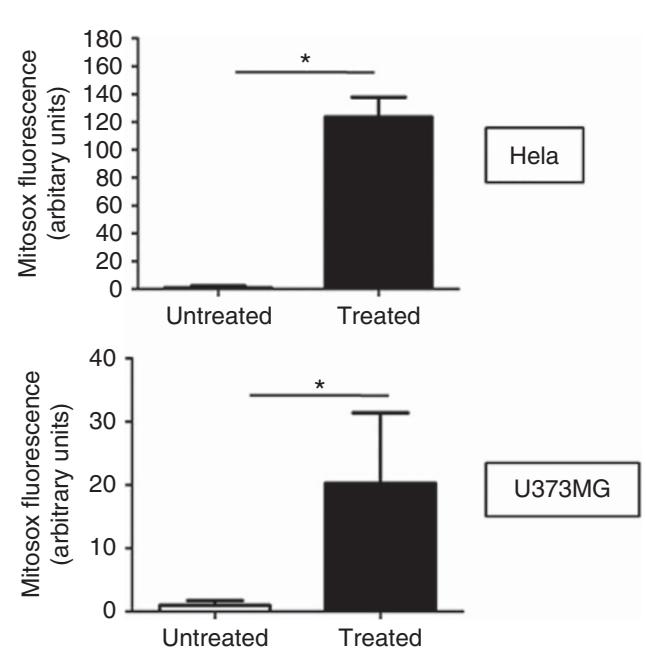

Figure 2. NTAP demonstrates an increase in ROS formation. (A) In situ verification of ROS production in both U373MG cells and HeLa cells was measured $1 \mathrm{~h}$ after NTAP exposure (75 kV for $180 \mathrm{~s}$ ) by confocal microscopy using $10 \mu \mathrm{m} \mathrm{H}_{2}$ DCFDA. (B) ROS fluorescence intensity was quantified spectrophotometrically, $1 \mathrm{~h}$ after NTAP exposure (75 kV for $180 \mathrm{~s})$. All experiments were repeated in triplicate. Statistical analysis was carried out using one-way ANOVA with Tukey's multiple comparison post-test ( ${ }^{\star}<0.05$ ). (C) ROS production in both U373MG and HeLa was also measured by flow cytometry using $0.1 \mu \mathrm{m} \mathrm{H}_{2}$ DCFDA. Fluorescence was quantified using the mean $\mathrm{H}_{2}$ DCFDA and compared with the untreated control $(P<0.001)$. (D) In situ verification of mitochondiral ROS production in both U373MG cells and HeLa cells was measured $1 \mathrm{~h}$ after NTAP exposure ( $75 \mathrm{kV}$ for $180 \mathrm{~s}$ ) by confocal microscopy using $2 \mu \mathrm{m}$ MitoSOX red. The level of fluorescence was quantified using the Image $\mathrm{J}$ software and compared with the untreated control. Statisical analysis was carried out using t-test with Mann-Whitney test post-test. A full colour version of this figure is available at the British Journal of Cancer journal online.

compared with HeLa cells ( $\mathrm{EC}_{50} 55.36 \mu \mathrm{M}$ ) (Figure 3B), and significant differences of the data set were confirmed using a correlation analysis (Supplementary Figure S4). The presence of intracellular and mitochondrial ROS was confirmed for both cell lines using confocal microscopy (Figure 3C).

NTAP can induces ROS-, JNK- and caspase-independent cell death in U373MG cells. Previously, it has been reported that NTAP induces ROS, JNK and caspase activation in cancer cells (Vandamme et al, 2011; Hou et al, 2015; Siu et al, 2015). To confirm the role of intracellular ROS in NTAP- and $\mathrm{H}_{2} \mathrm{O}_{2}$-induced apoptosis, HeLa and U373MG cells were loaded with the wellknown thiol antioxidant NAC for $48 \mathrm{~h}$ after NTAP treatment. As expected, the addition of NAC to $\mathrm{H}_{2} \mathrm{O}_{2}$-treated $\mathrm{HeLa}$ cells (Figure 4A) and U373MG cells (Figure 4B) improved cell viability $(P<0.05)$, indicating that NAC was protecting against ROSinduced cell death in both cell lines. Although NAC improved cell viability in HeLa cells following treatment of both cells and media with NTAP $(P<0.05)$ (Figure $4 \mathrm{~A})$, there was no protective effect noted for U373MG cells treated with NTAP (Figure 4B). Therefore, the data strongly suggest that unlike HeLa cells, U373MG cells undergo ROS-independent cell death in response to NTAP.

To further elucidate the molecular mechanism underlying U373MG apoptosis following NTAP treatment, the protective effect of increasing concentrations of the caspase inhibitor, zVAD-FMK and the JNK inhibitor, SP600125 was determined. No 

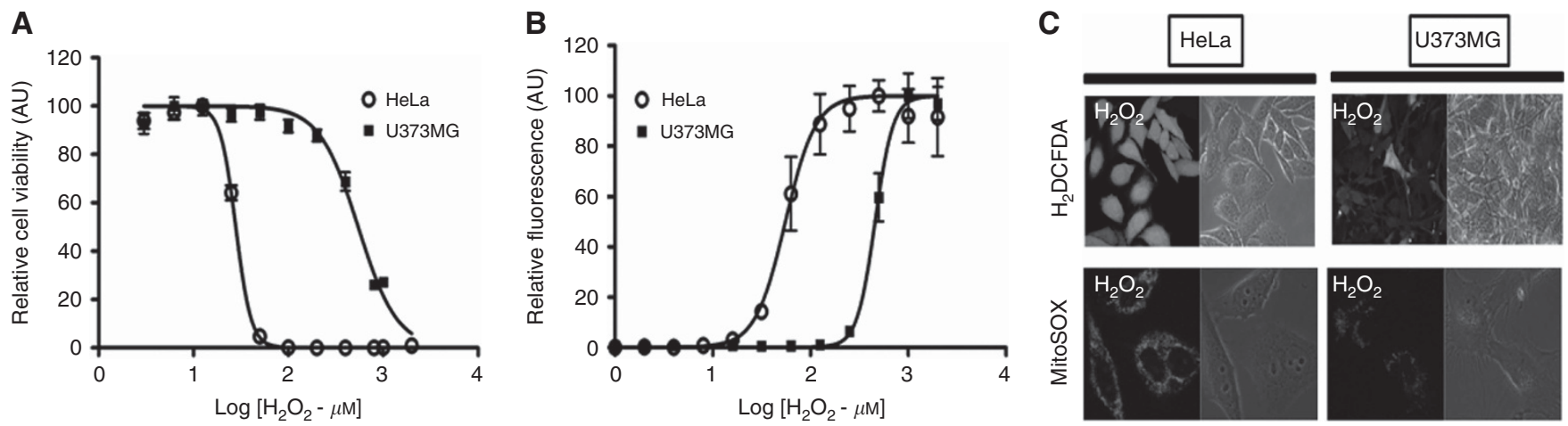

Figure 3. GBM cells demonstrate a higher antioxidant activity against $\mathrm{H}_{2} \mathrm{O}_{2}$. (A) Both U373MG cells and HeLa cells were treated with increasing concentrations of $\mathrm{H}_{2} \mathrm{O}_{2}(0-2 \mathrm{~mm})$. After $48 \mathrm{~h}$ cells were analysed using the Alamar Blue assay. All experiments were repeated at least three times. Statistical analysis was carried out using non-linear regression analyses. (B) Both U373MG cells and HeLa cells were preloaded for $1 \mathrm{~h}$ with $10 \mu \mathrm{M}$ $\mathrm{H}_{2}$ DCFDA. $\mathrm{H}_{2}$ DCFDA was removed and a dose-response analysis was performed using $\mathrm{H}_{2} \mathrm{O}_{2}$. The relative increase in fluroescence was determined $1 \mathrm{~h}$ after the addition of $\mathrm{H}_{2} \mathrm{O}_{2}$. Statistical analyses were carried out using non-linear regression analyses. All experiments were repeated minimum in triplicate. (C) In situ verification of ROS production in both U373MG cells and HeLa cells, which was measured $1 \mathrm{~h}$ after the addition of $\mathrm{H}_{2} \mathrm{O}_{2}$ by confocal microscopy using both $10 \mu \mathrm{M} \mathrm{H}_{2}$ DCFDA and $2 \mu \mathrm{m}$ MitoSOX red, is shown. A full colour version of this figure is available at the British Journal of Cancer journal online.
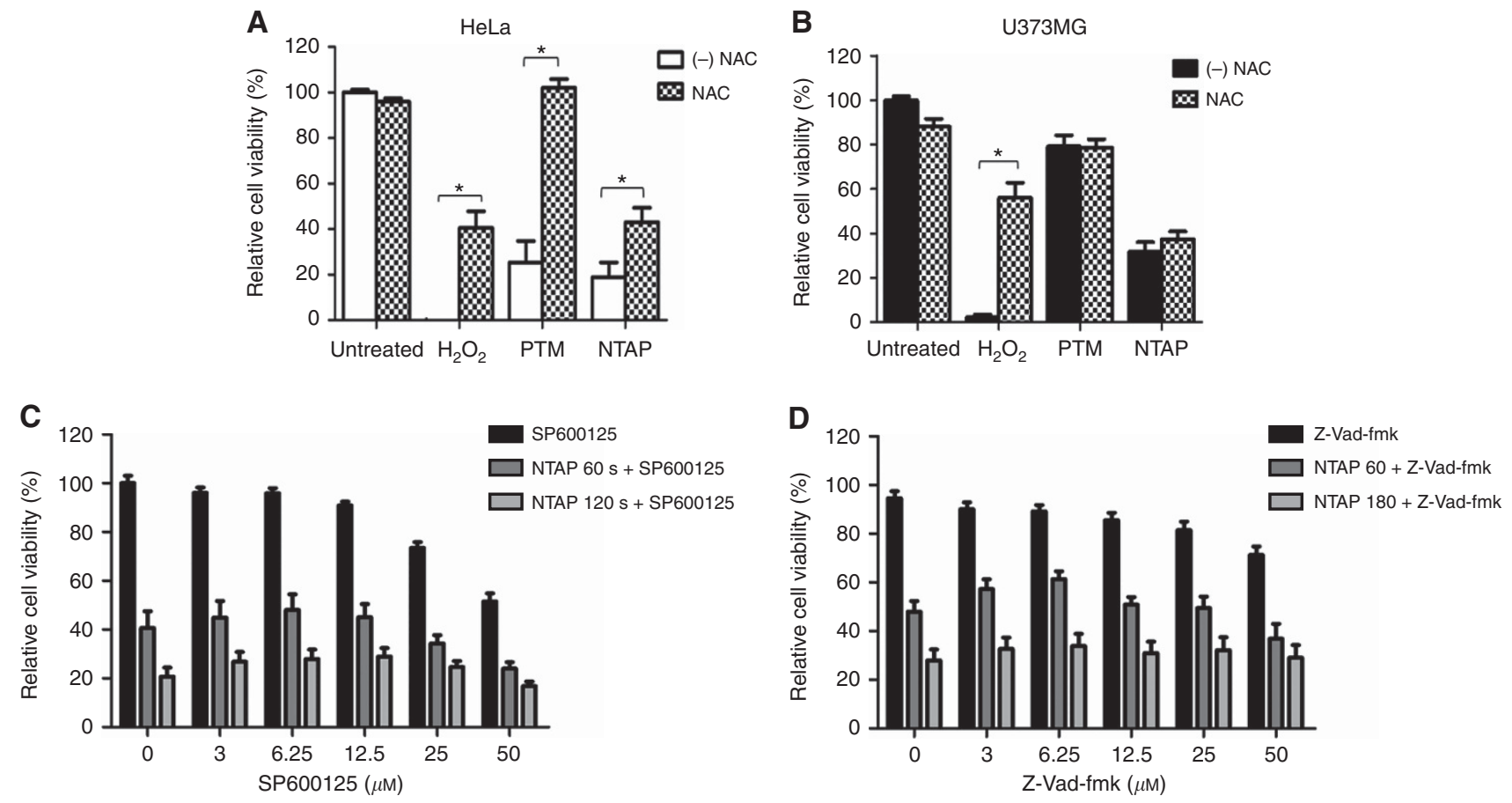

Figure 4. NTAP induces ROS-, JNK- and caspase-independent cytotoxicity in glioma cells. Both HeLa (A) and U373MG (B) cells were preloaded for $1 \mathrm{~h}$ with $4 \mathrm{~mm}$ NAC. Cells were then treated with $\mathrm{H}_{2} \mathrm{O}_{2}$ or exposed to NTAP. After $48 \mathrm{~h}$, cell was analysed using the Alamar blue assay. Data shown were normalised to the untreated control and are shown as the $\%$ mean \pm s.e.m. ( $n=$ minimum 20 ). All experiments were repeated at least three times. Statistical analysis was carried out using one-way ANOVA with Tukey's multiple comparison post test ( $\left.{ }^{\star} P<0.05\right)$. (C) Following NTAP treamtent, cells were loaded with increasing concentrations of SB600125 (0-50 $\mu \mathrm{m})$ inhibitor and incubated for $48 \mathrm{~h}$. Cells were then analysed using Alamar blue cell viability assay. (D) U373MG cells were pretreated with increasing concentrations of zVAD-FMK for $1 \mathrm{~h}$ before NTAP treatment. Cells were then incubated for $48 \mathrm{~h}$ and analysed by Alamar blue. Data shown were normalised to the untreated control and are shown as the \% mean \pm s.e.m. $(n=$ minimum 20$)$. All experiments were repeated at least three times.

significant difference in cell viability was observed with increasing concentrations of either SP600125 (Figure 4C) or zVAD-FMK (Figure 4D). There was also no significant difference in cell viability if cells were treated with the inhibitor before or after NTAP treatment. Together, our results indicate that NTAP induces apoptosis by an ROS-, JNK- and caspase-independent manner in GBM cells.

Multiple doses and TMZ overcome the relative resistance of U373MG cells to NTAP. If used in a clinical setting, NTAP or any variant of this technological therapy would most likely be used multiple times and in combination with existing chemotherapeutic regimens. We hypothesised that multiple treatments and/or combinational therapy with existing chemotherapeutic agents would be sufficient to overcome the relative resistance to NTAP. As seen in Figure 5A, triplicate NTAP exposures of $75 \mathrm{kV}$ for $180 \mathrm{~s}$ result in a significant reduction in U373MG cell viability compared with a single treatment $(5.669-43.16 \%, P<0.05)$. Furthermore, low doses $(10 \mu \mathrm{M})$ of TMZ greatly augmented the cytotoxicity observed 

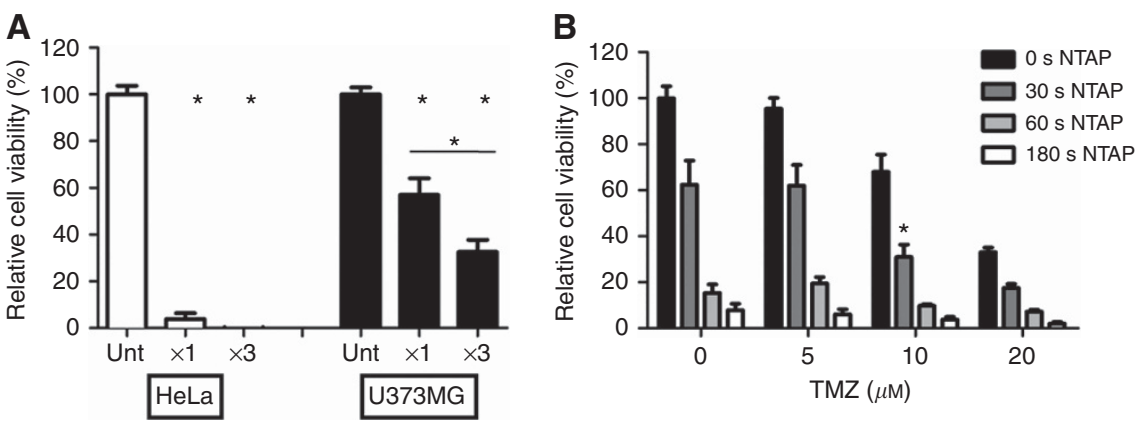

No. of NTAP treatments

Figure 5. Synergy observed between TMZ and NTAP. (A) The effects of multiple NTAP exposures were determined in both HeLa and U373MG. Cells were exposed three times within a 10-h period with a minimum $4 \mathrm{~h}$ between treatments. Forty-eight hours later, cells were then analysed using the Alamar blue assay. Results are shown as the mean \pm s.e.m. $(n=$ minimum 24$)$. Statistical analysis was carried out using one-way ANOVA with Tukey's multiple comparison post-test ( ${ }^{\star} P<0.05$ against untreated control). (B) Following NTAP treatment, cells were treated with low concentrations of TMZ. Cells were incubated for 6 days and analysed by Alamar blue assay. Data shown were normalised to the untreated control and are shown as the \% mean \pm s.e.m. ( $n=$ minimum 20). Statistical analysis was carried out using two-way ANOVA with Bonferroni post test $\left({ }^{\star} P<0.001\right)$. All experiments were repeated at least three times.

due to NTAP with toxicity levels approaching $80-100 \%$ (Figure 5B). Two-way ANOVA confirmed that there is variance in the data due to the combination of TMZ and NTAP, which cannot be explained by TMZ and NTAP alone. This indicates the presence of a synergistic effect as observed on the graph (Figure 5B) at $30 \mathrm{~s}$ NTAP and $10 \mu \mathrm{M}$ TMZ with $P<0.0001$. The $\mathrm{IC}_{50}$ for $\mathrm{TMZ}$ was determined to be $13 \mu \mathrm{M}$ over a 6 -day time course (data not shown).

\section{DISCUSSION}

GBMs are very aggressive and are resistant to most chemotherapies and radiation therapy (Curtin et al, 2005). Advances in wearable medical devices have led to the possibility of replacing or complementing existing chemotherapies using a technology-based approach. In this regard, there has been substantial development in the area of plasma medicine over the past decade, including the use of NTAP as a potential therapy for the treatment of cancer. It has been documented that ROS generated by NTAP treatment can induce apoptosis in glioma cells as well as many other cancer cells (Vandamme et al, 2012; Ahn et al, 2014; Siu et al, 2015). Our OES measurements confirmed notably larger emissions for nitrogen species and very little emissions at the atomic oxygen region of 777 and $845 \mathrm{~nm}$, in agreement with those reported by others using unmodified atmospheres and are as a result of quenching with $\mathrm{N}_{2}$ and $\mathrm{O}_{2}$ (Walsh et al, 2010; Misra et al, 2014). The presence of atomic oxygen is not required for the generation of ROS. Nonthermal atmospheric plasma generated NO results in intensification of intracellular NO concentration that initiates a cascade of event, subsequently increases intracellular ROS (Vandamme et al, 2012; Ishaq et al, 2014). In accordance with previous studies, the antiproliferative effect of NTAP treatment was confirmed in vitro (Ahn et al, 2011; Vandamme et al, 2012). The resistance to $\mathrm{H}_{2} \mathrm{O}_{2}$ induced apoptosis has been reported previously in GBM cells (Datta et al, 2002), but to the best of our knowledge, ROSindependent NTAP cytotoxicity has yet to be reported and characterised. We demonstrate here that U373MG GBM cells display a significant resistance to cytotoxicity and ROS generation $(P<0.0001)$ when compared with a commonly studied NTAPsensitive cancer cell line HeLa.

The current standard of care for the treatment of glioma involves repeated exposure to chemotherapy/radiation over a period of weeks/months in order to ensure eradication of the entire tumour. A similar effect was demonstrated with multiple exposures to NTAP, a triple exposure over a 10 -h period greatly enhanced cytotoxicity of the U373MG cells, indicating that NTAP can be both effective and cumulative against GBM. In the current clinical setting, radiation therapy is used in combination with surgery and chemotherapy to treat GBM. Non-thermal atmospheric plasma is also based on the formation of intracellular chemically active species. As the technology develops, the primary advantage of NTAP over radiotherapy will be the ability to generate these species in situ, at the site of the tumour and reduce the resulting systemic side effects (Ishaq et al, 2014). Moreover, the species generated by NTAP are short lived in comparison with the relatively long-lived radioactive isotopes introduced during radiation therapy (Stoffels et al, 2008). We were able confirm the generation of ROS by NTAP treatment in HeLa cells as previously reported by Ahn et al (2011). Reactive oxygen species generation was also observed in NTAP-treated U373MG cells (Figure 2) but, interestingly, at a significantly lower level compared with NTAPtreated HeLa cells. These results echoed $\mathrm{H}_{2} \mathrm{O}_{2}$-induced ROS levels, indicating that U373MG cells have a 5- to 10 -fold greater capacity to neutralise ROS compared with HeLa cells.

ROS, JNK and caspase activation have all been reported in cancer cells following NTAP treatment (Vandamme et al, 2011; Hou et al, 2015; Siu et al, 2015). We hypothesised that by activating multiple cell death pathways together, specific inhibition of these pathways would not be preventative of cell death after longer treatments of NTAP in U373MG cells. To test this hypothesis, we titrated common inhibitors of ROS, JNK and caspases. In line with previous findings (Köritzer et al, 2013), we found that caspase inhibitors do not protect against the effects of NTAP treatment. Furthermore, we were unable to protect against cell death using ROS scavengers or JNK inhibitors in GBM cells. It has been hypothesised that NTAP offers great potential as a possible therapy for the treatment of GBM due to the wide variety of biological processes affected and our own data are supporting this hypothesis. Our data suggest that several pathways have been activated simultaneously by the NTAP treatment, and blocking individual pathways is insufficient to inhibit cell death. To the best of our knowledge, this is the first evidence of a cell line where NTAP treatment can induce cell death even in the presence of JNK, Caspases and ROS inhibitors. In contrast to the results observed for HeLa cells, cytotoxicity in U373MG cells following NTAP treatment is not alleviated by the presence of NAC. $\mathrm{N}$-acetyl cysteine does protect against high concentrations $(2 \mathrm{mM})$ of $\mathrm{H}_{2} \mathrm{O}_{2}$ in U373MG cells. Therefore, NTAP is primarily inducing cell death through a $\mathrm{H}_{2} \mathrm{O}_{2}$ - and ROS-independent mechanism in U373MG cells. 
We observed that U373MG cells were relatively resistant to NTAP treatment, and so we looked at techniques to overcome this. We found that both multiple exposures to NTAP and use of low concentrations of TMZ were sufficient to overcome the relative resistance of U373MG cells to NTAP. Both these approaches led to an improved cytotoxicity of between $80 \%$ and $95 \%$, which is similar in magnitude to that observed when we use NTAP-sensitive cells such as HeLa cells (data not shown). Harsh side effects are associated with existing standard of care for patients diagnosed with GBM and despite this; very limited gains in long-term survival are evident. Therefore, lower doses of TMZ when used in combination with NTAP may lead to a more effective treatment while reducing the harmful side effects. Future development of micro-plasma technologies will greatly facilitate this specific targeting of GBM cells in the brain.

In conclusion, for the very first time, we report that NTAP induces an ROS-, JNK- and caspase-independent mechanism of cell death in the U373MG GBM cells that can be greatly enhanced when used in combination with low doses of TMZ or with cumulative exposures to NTAP. This highlights the potential of in situ NTAP generation as a future brain cancer therapy. Further refinement of the technology will be necessary and the generation of micro-scale plasma fields promises to facilitate localised activation of cytotoxicity against GBM cells when used in combination with new and existing chemotherapeutic regimens.

\section{ACKNOWLEDGEMENTS}

Financial support was provided by the Irish Research Council, IRCSET grant (post graduate fellowship scheme). This work was carried out in part in the FOCAS Institute DIT, funded under the Irish National Development Plan with assistance from the European Regional Development Plan.

\section{CONFLICT OF INTEREST}

The authors declare no conflict of interest.

\section{REFERENCES}

Adamson C, Kanu OO, Mehta AI, Di C, Lin N, Mattox AK, Bigner DD (2009) Glioblastoma multiforme: a review of where we have been and where we are going. Expert Opin Investig Drugs 18: 1061-1083.

Ahn HJ, Kim KI, Hoan NN, Kim CH, Moon E, Choi KS, Yang SS, Lee J-S (2014) Targeting cancer cells with reactive oxygen and nitrogen species generated by atmospheric-pressure air plasma. PLoS One 9: e86173.

Ahn HJ, Kim KI, Kim G, Moon E, Yang SS, Lee J-S (2011) Atmosphericpressure plasma jet induces apoptosis involving mitochondria via generation of free radicals. PLoS One 6: e28154.

Candolfi M, Curtin JF, Nichols WS, Muhammad AG, King GD, Pluhar GE, McNiel EA, Ohlfest JR, Freese AB, Moore PF, Lerner J, Lowenstein PR, Castro MG (2007) Intracranial glioblastoma models in preclinical neurooncology: neuropathological characterization and tumor progression. J Neurooncol 85: 133-148.

Carrabba G, Mukhopadhyay D, Guha A (2009) Aberrant signalling complexes in GBMs: prognostic and therapeutic implications. Glioblastoma: Molecular Mechanisms of Pathogenesis and Current Therapeutic Strategies. Springer Science and Business Media: New York, NY, USA, pp 95-130.

Cheng X, Sherman J, Murphy W, Ratovitski E, Canady J, Keidar M (2014) The effect of tuning cold plasma composition on glioblastoma cell viability. PLoS One 9: e98652.

Curtin JF, Donovan M, Cotter TG (2002) Regulation and measurement of oxidative stress in apoptosis. J Immunol Methods 265: 49-72.

Curtin JF, King GD, Candolfi M, Greeno RB, Kroeger KM, Lowenstein PR, Castro MG (2005) Combining cytotoxic and immune-mediated gene therapy to treat brain tumors. Curr Top Med Chem 5: 1151-1170.
Datta K, Babbar P, Srivastava T, Sinha S, Chattopadhyay P (2002) p53 dependent apoptosis in glioma cell lines in response to hydrogen peroxide induced oxidative stress. Int J Biochem Cell Biol 34: 148-157.

Dolecek TA, Propp JM, Stroup NE, Kruchko C (2012) CBTRUS statistical report: primary brain and central nervous system tumors diagnosed in the United States in 2005-2009. Neuro Oncol 14(Suppl 5): v1-v49.

Fridman G, Friedman G, Gutsol A, Shekhter AB, Vasilets VN, Fridman A (2008) Applied plasma medicine. Plasma Process Polym 5: 503-533.

Fridman G, Peddinghaus M, Balasubramanian M, Ayan H, Fridman A, Gutsol A, Brooks A (2006) Blood coagulation and living tissue sterilization by floating-electrode dielectric barrier discharge in air. Plasma Chem Plasma Process 26: 425-442.

Galluzzi L, Zamzami N, de La Motte Rouge T, Lemaire C, Brenner C, Kroemer G (2007) Methods for the assessment of mitochondrial membrane permeabilization in apoptosis. Apoptosis 12: 803-813.

Hirst AM, Simms MS, Mann VM, Maitland NJ, O'Connell D, Frame FM (2015) Low-temperature plasma treatment induces DNA damage leading to necrotic cell death in primary prostate epithelial cells. $\mathrm{Br} J$ Cancer 112: $1536-1545$

Hou J, Ma J, Yu KN, Li W, Cheng C, Bao L, Han W (2015) Non-thermal plasma treatment altered gene expression profiling in non-small-cell lung cancer A549 cells. BMC Genomics 16: 435.

Ishaq M, Evans MM, Ostrikov KK (2014) Effect of atmospheric gas plasmas on cancer cell signaling. Int J Cancer 134: 1517-1528.

Kim K, Jun Ahn H, Lee J-H, Kim J-H, Sik Yang S, Lee J-S (2014) Cellular membrane collapse by atmospheric-pressure plasma jet. Appl Phys Lett 104: 013701.

King RJB, Robins MW (2006) Chemical and radiation carcinogenesis. Cancer Biology. Pearson Education: England, UK, pp 96-97.

Köritzer J, Boxhammer V, Schäfer A, Shimizu T, Klämpfl TG, Li Y-F, Welz C, Schwenk-Zieger S, Morfill GE, Zimmermann JL, Schlegel J (2013) Restoration of sensitivity in chemo-resistant glioma cells by cold atmospheric plasma. PLoS One 8: e64498.

Lin C-J, Lee C-C, Shih Y-L, Lin T-Y, Wang S-H, Lin Y-F, Shih C-M (2012) Resveratrol enhances the therapeutic effect of temozolomide against malignant glioma in vitro and in vivo by inhibiting autophagy. Free Radic Biol Med 52: 377-391.

Louis DN, Ohgaki H, Wiestler OD, Cavenee WK, Burger PC, Jouvet A, Scheithauer BW, Kleihues P (2007) The 2007 WHO classification of tumours of the central nervous system. Acta Neuropathol 114: 97-109.

Ma Y, Ha CS, Hwang SW, Lee HJ, Kim GC, Lee K-W, Song K (2014) Non-thermal atmospheric pressure plasma preferentially induces apoptosis in p53-mutated cancer cells by activating ROS stress-response pathways. PLoS One 9: e91947.

McCloy RA, Rogers S, Caldon CE, Lorca T, Castro A, Burgess A (2014) Partial inhibition of Cdk1 in $\mathrm{G} 2$ phase overrides the SAC and decouples mitotic events. Cell Cycle 13: 1400-1412.

Misra NN, Pankaj SK, Walsh T, O’Regan F, Bourke P, Cullen PJ (2014) In-package nonthermal plasma degradation of pesticides on fresh produce. J Hazard Mater 271: 33-40.

Ostrom QT, Gittleman H, Liao P, Rouse C, Chen Y, Dowling J, Wolinsky Y, Kruchko C, Barnholtz-Sloan J (2014) CBTRUS statistical report: primary brain and central nervous system tumors diagnosed in the United States in 2007-2011. Neuro Oncol 16(Suppl 4): iv1-iv63.

Page B, Page M, Noel C (1993) A new fluorometric assay for cytotoxicity measurements in-vitro. Int J Oncol 3: 473-476.

Recek N, Cheng X, Keidar M, Cvelbar U, Vesel A, Mozetic M, Sherman J (2015) Effect of cold plasma on glial cell morphology studied by atomic force microscopy. PLoS One 10: e0119111.

Salido M, Gonzalez JL, Vilches J (2007) Loss of mitochondrial membrane potential is inhibited by bombesin in etoposide-induced apoptosis in PC-3 prostate carcinoma cells. Mol Cancer Ther 6: 1292-1299.

Siu A, Volotskova O, Cheng X, Khalsa SS, Bian K, Murad F, Keidar M, Sherman JH (2015) Differential effects of cold atmospheric plasma in the treatment of malignant glioma. PLoS One 10: e0126313.

Stoffels E, Sakiyama Y, Graves DB (2008) Cold atmospheric plasma: charged species and their interactions with cells and tissues. IEEE Trans Plasma Sci 36: 1441-1457.

Vandamme M, Robert E, Dozias S, Sobilo J, Lerondel S, Le Pape A, Pouvesle J-M (2011) Response of human glioma U87 xenografted on mice to non thermal plasma treatment. Plasma Med 1: 27-43.

Vandamme M, Robert E, Lerondel S, Sarron V, Ries D, Dozias S, Sobilo J, Gosset D, Kieda C, Legrain B, Pouvesle J-M, Pape AL (2012) 
ROS implication in a new antitumor strategy based on non-thermal plasma. Int J Cancer 130: 2185-2194.

Walsh JL, Liu DX, Iza F, Rong MZ, Kong MG (2010) Contrasting characteristics of sub-microsecond pulsed atmospheric air and atmospheric pressure helium-oxygen glow discharges. J Phys D Appl Phys 43: 032001.

von Woedtke T, Reuter S, Masur K, Weltmann K-D (2013) Plasmas for medicine. Phys Rep 530: 291-320.

Wu D, Yotnda P (2011) Production and detection of reactive oxygen species (ROS) in cancers. J Vis Exp pii: 3357.

Xu D, Liu D, Wang B, Chen C, Chen Z, Li D, Yang Y, Chen H, Kong MG (2015) In situ $\mathrm{OH}$ generation from $\mathrm{O} 2$ - and $\mathrm{H} 2 \mathrm{O} 2$ plays a critical role in plasma-induced cell death. PLoS One 10: e0128205.
Ziuzina D, Patil S, Cullen PJ, Keener KM, Bourke P (2013) Atmospheric cold plasma inactivation of Escherichia coli in liquid media inside a sealed package. J Appl Microbiol 114: 778-787.

Ziuzina D, Patil S, Cullen PJ, Keener KM, Bourke P (2014) Atmospheric cold plasma inactivation of Escherichia coli, Salmonella enterica serovar Typhimurium and Listeria monocytogenes inoculated on fresh produce. Food Microbiol 42: 109-116.

This work is published under the standard license to publish agreement. After 12 months the work will become freely available and the license terms will switch to a Creative Commons AttributionNonCommercial-Share Alike 4.0 Unported License.

Supplementary Information accompanies this paper on British Journal of Cancer website (http://www.nature.com/bjc) 